\title{
Secteur 6 : vallées de l'Orne (54), de la Gorzia (57) et secteurs d'Amel-sur-l'Étang et Senon
}

Denis Jacquemot

\section{(2) OpenEdition Journals}

Édition électronique

URL : http://journals.openedition.org/adlfi/9100

ISSN : 2114-0502

Éditeur

Ministère de la culture

Référence électronique

Denis Jacquemot, « Secteur 6 : vallées de l'Orne (54), de la Gorzia (57) et secteurs d'Amel-sur-l'Étang et Senon », ADLFI. Archéologie de la France - Informations [En ligne], Lorraine, mis en ligne le 01 mars 2001, consulté le 23 avril 2019. URL : http://journals.openedition.org/adlfi/9100

Ce document a été généré automatiquement le 23 avril 2019

(C) Ministère de la Culture et de la Communication, CNRS 


\title{
Secteur 6 : vallées de l'Orne (54), de la Gorzia (57) et secteurs d'Amel- sur-l'Étang et Senon
}

\author{
Denis Jacquemot
}

Identifiant de l'opération archéologique : F1354200100072

Date de l'opération : $2001(\mathrm{PA})$

\section{AMEL-SUR-L'ÉTANG (55), La Petite Hayette}

2 Plusieurs taches et zones d'épandage pierreuse à proximité immédiate de l'amphithéâtre et de l'ensemble cultuel découverts l'an dernier en prospection aérienne.

3 AMEL-SUR-L'ÉTANG (55), La Lampe

4 Anomalies circulaires pleines et fossoyées, incluses dans un enclos quadrangulaire.

5 GIRAUMONT (57), nord du lieu-dit Les Grands Prés

6 Ensemble de cercles fossoyés de type funéraires (?) dont certains sont polylobés

7 DOMMARY-BARONCOURT (55), Chaud Soleil

8 Grand enclos quadrangulaire fossoyé dans lequel on aperçoit deux fosses à l'angle et au centre de la structure.

9 NOVÉANT-SUR-MOSELLE (57), Le Jambon le Clou

10 Apparition d'un troisième tronçon de l'aqueduc romain de Gorze à Metz dans une parcelle en culture.

11 SAINT-MARCEL (54), Bois Pierrot

12 Tronçon et fossé de la voie romaine de Metz à Reims qui matérialisent la limite communale et départementale entre Saint-Marcel et Vionville.

13 (Fig. $n^{\circ} 1$ : Dommary-Baroncourt, Chaud Soleil - Enclos quadrangulaire fossoyé) 


\section{ANNEXES}

Fig. $n^{\circ} 1$ : Dommary-Baroncourt, Chaud Soleil - Enclos quadrangulaire fossoyé

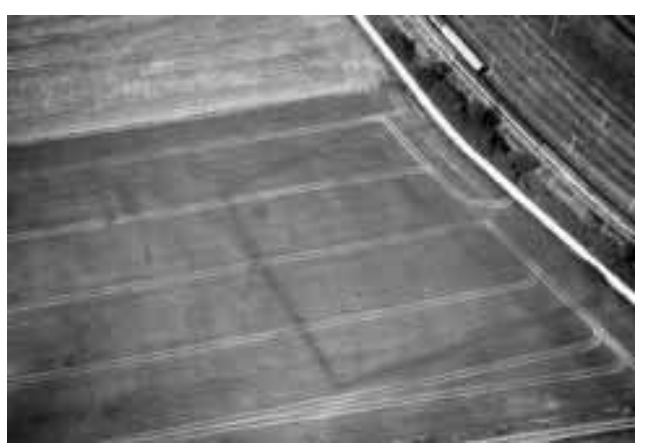

Auteur(s) : Jacquemot, Denis (Autre). Crédits : Jacquemot Denis (2001)

INDEX

Index géographique : Lorraine

Thèmes : amphithéâtre, aqueduc, enclos quadrangulaire, fosse, voie romaine operation Prospection aérienne (PA)

\section{AUTEURS}

DENIS JACQUEMOT 